\title{
1 Microbial community assembly differs by mineral type in the rhizosphere
}

3 Thea Whitman ${ }^{1,2^{*}}$, Rachel Neurath ${ }^{1,5}$, Adele Perera ${ }^{1}$, Daliang Ning ${ }^{3}$, Jizhong Zhou ${ }^{3,4,5}$, Peter

$4 \mathrm{Nico}^{4}$, Jennifer Pett-Ridge ${ }^{6}$, and Mary Firestone ${ }^{1,4}$

${ }^{1}$ Department of Environmental Science Policy and Management, University of CaliforniaBerkeley; ${ }^{2}$ Department of Soil Science, University of Wisconsin-Madison; ${ }^{3}$ Institute for

8 Environmental Genomics, Department of Microbiology and Plant Biology, and School of Civil

9 Engineering and Environmental Sciences, University of Oklahoma; ${ }^{4}$ Earth and Environmental

10 Sciences, Lawrence Berkeley National Laboratory; ${ }^{5}$ State Key Joint Laboratory of Environment

11 Simulation and Pollution Control, School of Environment, Tsinghua University, Beijing, China;

$12{ }^{6}$ Physical and Life Science Directorate, Lawrence Livermore National Laboratory;

$13{ }^{*}$ Corresponding author

15 Subject category: Microbial ecology and functional diversity of natural habitats

\section{Abstract}

18 Inputs of root carbon (C) fuel growth of nearby soil microorganisms. If these microbes associate

19 with soil minerals, then mineral-microbiome complexes near roots could be a gateway towards

20 stabilization of soil carbon and may influence the quantity and quality of persistent SOM. To

21 investigate the interactions between roots, soil minerals, and microbes, we incubated three types

22 of minerals (ferrihydrite, kaolinite, quartz) and a native soil mineral fraction near roots of a

23 common Californian annual grass, Avena barbata, growing in its resident soil. We followed

24 microbial colonization of these minerals for 2.5 months - the plant's lifespan. Bacteria and fungi

25 that colonized mineral surfaces during this experiment differed across mineral types and differed

26 from those in the background soil, implying microbial colonization was the result of processes in

27 addition to passive movement with water to mineral surfaces. Null model analysis revealed that

28 dispersal limitation was a dominant factor structuring mineral-associated microbial communities

29 for all mineral types. Once bacteria arrived at a mineral surface, capacity for rapid growth

30 appeared important, as ribosomal copy number was significantly correlated with relative

31 enrichment on minerals. Glomeromycota (a phylum associated with arbuscular mycorrhizal 
32 fungi) appeared to preferentially associate with ferrihydrite surfaces. The mechanisms enabling

33 colonization of soil minerals may be foundational to the overall soil microbiome composition

34 and partially responsible for the persistence of $\mathrm{C}$ entering soil via plant roots.

\section{Introduction}

38 Plant roots and the microorganisms that surround them are critically important to soil C

39 stabilization, as roots are the primary source of stabilized organic C in soil (Dijkstra and Cheng,

40 2007; Clemmensen et al., 2013; Drake et al., 2011; Treseder and Holden, 2013). This input of

41 organic carbon fuels the growth of mineral-associated microbes that drive many critical soil

42 processes, including mineral weathering (Banfield et al., 1999; Uroz et al., 2009), aggregate

43 formation (Six and Paustian, 2014) and the cycling of mineral-sorbed organic matter (Saidy et

44 al., 2014; Schmidt et al., 2011). Mineral sorption of soil organic matter (SOM) is thought to play

45 an important role in limiting the microbial availability of soil $\mathrm{C}$ and contributing to the

46 persistence of C in soils (Keiluweit et al., 2015; Schmidt et al., 2011), but is not well understood

47 in the rhizosphere, where levels of organic inputs, exudates, and microbial activity are high

48 (Kuzyakov and Blagodatskaya, 2015). Understanding the processes that control such mineral-

49 SOM-microbe interactions is essential to understanding how microbial communities affect soil C

50 cycling (Kallenbach et al., 2016).

52 Given that one gram of soil may contain a billion bacterial cells, the patchiness of soil microbial

53 communities can be surprising (Raynaud and Nunan, 2014). In most soils, mineral surfaces are

54 not fully colonized by microbes (Nunan et al.; Ranjard and Richaume, 2001; Vos et al., 2013),

55 and are not "saturated" with organic matter (Kögel-Knabner et al., 2008; Miltner et al., 2011;

56 Lehmann et al., 2007). Fresh mineral surfaces are constantly regenerated in surface soils through

57 the dynamic processes of mineral weathering and formation. While the canonical role of lichens

58 in rock colonization and subsequent soil formation is well described (Chen et al., 2000; Raab et

59 al., 2012; Cooper and Rudolph, 1953; Hodkinson et al., 2002)), we know little about the first

60 inhabitants of minerals as they form within the soil (Hutchens, 2009). In addition to the

61 formation of new microhabitats through mineral weathering, frequent disturbances, ranging from

62 large-scale climatic changes (Pold and DeAngelis, 2013) to the millimeter-scale incursion of 
63 roots (Belnap et al., 2003), regularly "reset" microscale communities (DeAngelis et al., 2008).

64 These disruptions ensure that meaningful "stable states" or "climax communities" are rare, and

65 microbial colonization processes are likely important determinants of soil microbial community

66 composition. Studying microbial colonization of "fresh" soil minerals (i.e., minerals free of SOM

67 and cells) can provide insight into microbial community assembly in the "mineralosphere" (Uroz

68 et al., 2009) and in soils as a whole. In addition, microbial interactions with minerals have

69 important implications for mineral dynamics, affecting metal speciation, toxicity, mobility,

70 mineral formation, and mineral dissolution (Gadd, 2010).

72 Surface attachment confers important advantages for soil microorganisms, including protection

73 from predation, access to nutrients or energy sources, and provision of a substrate for biofilm

74 formation or other density-dependent phenomena (Hutchens, 2009; Uroz et al., 2015). However,

75 soil minerals can provide much more than simply an attachment surface. Different minerals offer

76 specific chemical or physical environments - e.g., varying in surface area, redox status, or

77 chemical composition (Banfield and Hamers, 1997) - which may regulate the degree of

78 microbial colonization and even community composition. For example, (Hutchens et al., 2010)

79 found significantly different bacterial and fungal communities colonized different granitic

80 minerals within the same exposed rocky outcrop. However, very few mineral colonization

81 studies have been done in a soil context (Uroz et al., 2015). Uroz et al. (2012) found that

82 different communities colonized minerals (pure apatite, pure plagioclase and a mix of

83 phlogopite-quartz) after four years of burial in acidic forest soils, while Wilson et al. (2008)

84 found that while some minerals were more intensively colonized, magnetically-separated Fe-

85 /Mg- minerals vs. volcanic glass or K-feldspar minerals had similar microbial community

86 composition in a volcanic soil. Clearly, the effect of soil mineralogy on microbial colonization of

87 fresh minerals and the mechanisms that control their community assembly processes require

88 additional investigation (Uroz et al., 2015). In our study, we explored these phenomena within a

89 rhizosphere context, where altered chemical and resource characteristics create a unique

90 environment.

92 The factors that shape community assembly (Maherali and Klironomos, 2007; Keddy, 1992;

93 Drake, 1990; Tilman, 2004) and community succession within new habitats (Hodkinson et al., 
94 2002; Gleason, 1939; Young et al., 2001) have long been studied for macrobiota. Similar

95 principles may be applied to understand assembly of microbial communities. For example, in a

96 fluid ecosystem, Zhou et al. (2014) evaluated the concepts of deterministic versus stochastic

97 processes, showing that both processes played important roles, but their relative importance

98 varied over time. In our study of microbe-scale colonization of fresh mineral surfaces within the

99 rhizosphere, we considered a number of central questions. Are community members passively

100 transported or do they actively move to new microhabitats? Once microbes arrive at a new

101 microhabitat, does selection favor certain organisms from the source community, or is a novel

102 community drawn indiscriminately from the surrounding rhizosphere soil? We investigated

103 which microbes colonize "fresh" mineral surfaces in the soil, what community assembly

104 processes determine initial community composition in the mineralosphere, and the characteristics

105 that make microbes strong colonizers of mineral surfaces in rhizosphere soil. To address these

106 questions, we incubated fresh minerals commonly found in our study soil (quartz, kaolinite, and

107 ferrihydrite) as well as density-fractionated native soil minerals ("heavy fraction") in soil

108 microcosms planted with the annual grass Avena barbata for up to 2.5 months. We then assessed

109 how root presence and different minerals selected for distinct fungal, bacterial, and archaeal

110 communities in the soil. We tested whether the microbial composition of the fresh minerals came

111 to resemble that of the surrounding soil (communities dominated by homogenizing selection and

112 homogenizing dispersal), or whether some degree of community structuring was driven by

113 differences in minerals (variable selection or dispersal limitation). We tested whether the

114 microbial composition of the fresh minerals came to resemble that of the surrounding soil

115 (communities dominated by homogenizing selection and homogenizing dispersal), or whether

116 some degree of community structuring was driven by differences in minerals (variable selection

117 or dispersal limitation).

118

119 Materials and Methods

120 Experimental design

121 Avena barbata (wild oat) plants were grown in a soil from a California annual grassland that

122 supports $A$. barbata as a dominant grass species. The soil is a fine-loamy, mixed, active, mesic

123 Typic Haploxeralf (properties described in Supplementary Table 1) collected from 0-10 cm

124 depth in a pasture at the UC Hopland Research and Extension Centre $\left(38.992938^{\circ} \mathrm{N}\right.$, - 
$\left.125123.067714^{\circ} \mathrm{W}\right)$. It was sieved to $<2 \mathrm{~mm}$ and packed at field density $\left(1.21 \mathrm{~g} \mathrm{~cm}^{-3}\right)$ into

126 mesocosms with a removable side panel (described in (DeAngelis et al., 2008; Jaeger et al.,

127 1999). Plants (4 per microcosm - equivalent to field density) were grown under $14 \mathrm{hr}$ full

128 spectrum light, at $14 \% \%_{\mathrm{vwc}}$ moisture, and $400 \mathrm{ppm} \mathrm{CO}_{2}$ for 1 month in the main chamber, after

129 which the microcosms were opened, the side panel was removed, and 10 mineral bags (3 each of

130 ferrihydrite, quartz, and kaolinite, and one of the heavy fraction; description follows) were

131 placed directly on top of the roots and soil in a randomized order, covered with additional fresh

132 soil, and the microcosms were resealed (Figure 1). Five microcosms were opened and mineral

133 bags were destructively harvested after 1 month, 2 months, and 2.5 months of incubation, at

134 which point plants were beginning to show signs of senescence. We also collected soil at this

135 time. Soil was separated from coarse roots and passed through $<2 \mathrm{~mm}$ sieve to homogenize it,

136 and then sub-sampled and preserved for analysis. All mineral and soil samples were immediately

137 frozen on dry ice and placed in a $-80^{\circ} \mathrm{C}$ freezer for storage within the day.

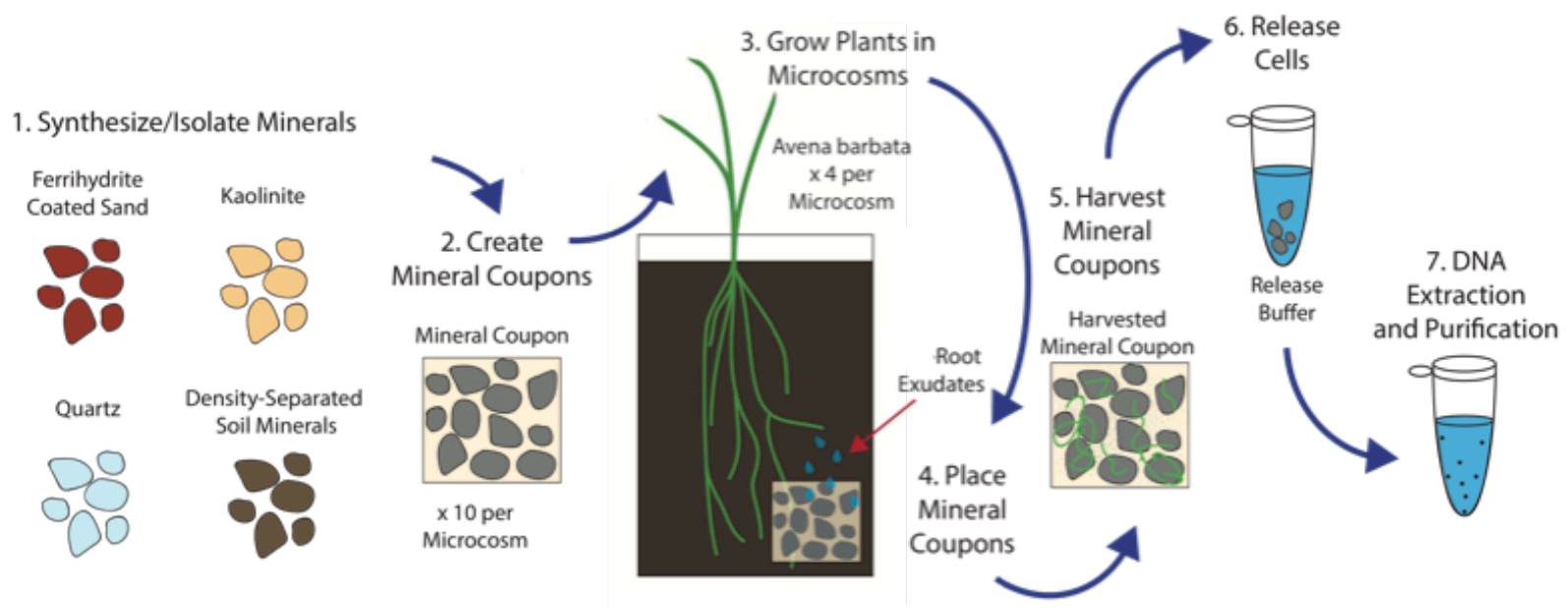

141 Figure 1. Experimental design conceptual figure. Ferrihydrite, kaolinite, and quartz minerals

142 with pure, C-free surfaces and density-separated soil minerals were incubated in soil microcosms

143 with growing Avena barbata. Minerals were harvested and immediately transferred to a cell

144 release buffer and then DNA was extracted and purified for sequencing and qPCR.

146 Mineral preparation and properties are described in detail in Neurath et al. (in prep) and are

147 summarized in Table 1. Briefly, X-ray diffraction (XRD) analysis of Hopland soil was used to 
148 identify the dominant clay mineral and iron oxide used in this study: kaolinite and ferrihydrite,

149 respectively. Hopland soil also contains quartz, which we used as a "control" mineral due to its

150 low surface area and less-reactive surface. Density fractionation (modified method by Sollins et

151 al. (2006)) was used to separate the "heavy fraction" ( $\left.>1.75 \mathrm{~g}-\mathrm{cm}^{-3}\right)$ component of Hopland soil

152 from free light and occluded light fractions. The heavy fraction was then lyophilized before use

153 in this experiment. Quartz sand was acid washed in 10\% $\mathrm{HCl}$. Ferrihydrite-coated quartz was

154 synthesized in the lab, with $\mathrm{Al}$ and $\mathrm{Si}$ inclusion to better represent a natural ferrihydrite mineral.

155 Kaolinite was mixed with quartz at a 1:1 per mass ratio to moderate potential clumping effects of

156 pure clay. Minerals were sealed in $18 \mu$ m nylon mesh bags measuring 5 x 5 x $0.2 \mathrm{~cm}$, with a

157 single mineral type in each bag: density-separated heavy fraction; quartz; ferrihydrite-coated

158 quartz ("ferrihydrite"); and the 50:50 kaolinite:quartz mix ("kaolinite"). The quartz, ferrihydrite,

159 and kaolinite minerals had an initial $\mathrm{C}$ content of $0 \%$, while the heavy fraction had an initial C

160 content of $1.6 \%$.

161

Table 1. Mineral properties

\begin{tabular}{|c|c|c|c|c|}
\hline Property & Quartz & Pure Kaolinite* & Ferrihydrite & Heavy fraction \\
\hline Chemical formula & $\mathrm{SiO}_{4}$ & $\mathrm{Al}_{2} \mathrm{Si}_{2} \mathrm{O}_{5}(\mathrm{OH})_{4}$ & $\mathrm{Fe}(\mathrm{OH})_{3}$ & NA \\
\hline Source of mineral & $\begin{array}{l}\text { Purchased from } \\
\text { Sigma-Aldrich, } \\
(274739)\end{array}$ & $\begin{array}{l}\text { Kaolinite } \\
\text { purchased from } \\
\text { the Clay } \\
\text { Minerals Society } \\
(\mathrm{K}-\mathrm{Ga} 2)\end{array}$ & $\begin{array}{l}\text { Synthesized in lab } \\
\text { following (Hansel } \\
\text { et al., 2003) }\end{array}$ & $\begin{array}{l}\text { Extracted from } \\
\text { soil using } \\
\text { modified protocol } \\
\text { from (Sollins et } \\
\text { al., 2006) }\end{array}$ \\
\hline $\begin{array}{l}\text { BET surface area } \\
\left(\mathrm{m}^{2} \mathrm{~g}^{-1}\right)\end{array}$ & $0.01-0.05 * *$ & 20.48 & 4.8 & 2.68 \\
\hline Particle size range & $297-210 \mu \mathrm{m}$ & Mostly $<2 \mu \mathrm{m}$ & Coated quartz & Not determined \\
\hline Initial C (\%) & Negligible & Negligible & Negligible & 1.6 \\
\hline $\begin{array}{l}\text { Predicted relative } \\
\text { charge density }\end{array}$ & Very low & Low & High & Intermediate \\
\hline $\begin{array}{l}\text { Primary or } \\
\text { secondary mineral? }\end{array}$ & Primary & Secondary & Secondary & NA \\
\hline
\end{tabular}

$\ddagger \mathrm{N}_{2}$ analysis gas

* Kaolinite was used in a 50:50 mixture with quartz

** Quartz surface area was too low to measure using the above techniques with $\mathrm{N}_{2}$ gas. 


\section{DNA extraction}

165 At harvest, minerals and bulk soil samples were transferred to Whirl-pak bags, frozen on dry ice,

166 and stored at $-80^{\circ} \mathrm{C}$. Anticipating potential difficulty in DNA desorption from the ferrihydrite

167 minerals in particular, we used a sterile cell release buffer of Tween $20\left(5 \mathrm{~g} \mathrm{~L}^{-1}\right)$ and sodium

168 pyrophosphate decahydrate $\left(1 \mathrm{~g} \mathrm{~L}^{-1}\right)$ (Supplementary Note 1$)$. Released cells were processed

169 using a modified phenol-choloroform DNA extraction protocol (Griffiths et al., 2000; Shi et al.,

170 2015). Briefly, samples received $500 \mu \mathrm{L} \mathrm{5 \%} \mathrm{CTAB} \mathrm{/} \mathrm{0.7M} \mathrm{NaCl} \mathrm{/} 240 \mathrm{mM} \mathrm{K-PO}$ at pH 8, 500

$171 \mu \mathrm{L}$ of 25:24:1 phenol/chloroform/isoamyl alcohol, and lysing matrix E beads (MP Biomedicals,

172 Santa Ana, CA). Tubes were shaken on a FastPrep (MP Biomedicals, Santa Ana, CA) for $30 \mathrm{~s}$ on

173 speed 5.5. After centrifuging at $4{ }^{\circ} \mathrm{C}$, the aqueous phase was transferred to $2 \mathrm{~mL}$ phase-lock gel

174 heavy tubes (5 Prime), where they received an equal amount of 24:1 chloroform/isoamyl alcohol,

175 were mixed, centrifuged, and then the aqueous phase was transferred to $1 \mathrm{~mL} 40 \%$ PEG 6000 /

$1761.6 \mathrm{M} \mathrm{NaCl}$, where DNA precipitated for $1 \mathrm{~h}$. Extracted samples were then re-extracted with 500

$177 \mu \mathrm{L}$ CTAB mixture, with the resulting aqueous extract added to the PEG 6000 tubes, along with 1

$178 \mu \mathrm{L}$ linear acrylamide as a co-extractant. Samples were then centrifuged for 20 minutes at $4^{\circ} \mathrm{C}$,

179 supernatant removed, and then DNA pellets rinsed with $70 \% \mathrm{EtOH}$, air-dried, and resuspended

180 in $50 \mu \mathrm{L}$ RNAase-free water, and frozen at $-80^{\circ} \mathrm{C}$. DNA was quantified using a Quant-iT

181 PicoGreen double stranded DNA assay kit (Invitrogen, Carlsbad, CA) and a BioRad iCycler

182 (BioRad Laboratories, Hercules, CA).

183

184 Quantitative PCR

185 The 16S rRNA gene and ITS DNA copies in each sample were determined using quantitative

186 PCR (qPCR) with primer sets EUB338/EUB518 for bacteria and 5.8S/ITS 1f for fungi

187 (Supplementary Table 2) (Fierer et al., 2005), using a BioRad iCycler (BioRad Laboratories,

188 Hercules, CA) and SSOFast EvaGreen Supermix (BioRad Laboratories, Hercules CA). Samples

189 were run in triplicate $(10 \mu \mathrm{L}$ EvaGreen supermix $2 \mathrm{X}, 1 \mu \mathrm{L} 10 \mu \mathrm{M}$ f primer, $1 \mu \mathrm{L} 10 \mu \mathrm{M}$ reverse

190 primer, $1 \mu \mathrm{L}(1: 100$ diluted $)$ template $\mathrm{DNA}$, and $7 \mu \mathrm{L} \mathrm{H}_{2} \mathrm{O}$; reaction was $95^{\circ} \mathrm{C}$ for $5 \mathrm{~min}$, [95 ${ }^{\circ} \mathrm{C}$

191 for $10 \mathrm{~s}, 62^{\circ} \mathrm{C}$ for $\left.20 \mathrm{~s}\right] \times$ x 40 ). 


\section{$16 S$ and ITS2 sequencing}

195 We used a two-step PCR to prepare amplicon libraries as described previously (Wu et al., 2015).

196 For the first step, primer sets used for amplification of the ITS2 and 16S genes were

197 gITS7F/ITS4R (fungal ITS2) (White et al., 1990), and 515F/808R (bacterial and archaeal 16S v4

198 region) (Supplementary Table 2). Procedures differed from Wu et al. (2015) in amplification

199 cycles (10 cycles in the first step and 20 cycles in the second step for 16S; 12 cycles in the first

200 step and 22 cycles in the second step for ITS). For the second step, phasing primers were used to

201 increase base diversity in sample library sequences. Sample libraries were sequenced on a MiSeq

202 system (Illumina, San Diego, CA, USA) (2x250bp paired ends) at the Institute for Environmental

203 Genomics, University of Oklahoma.

\section{$16 S$ and ITS sequence data analysis}

206 For processing and analyzing the 16S data, we drew on methods from (Pepe-Ranney et al., 2015;

207 McMurdie and Holmes, 2013). We used Paired End reAd mergeR (PEAR) (Zhang et al., 2014)

208 to merge reads, screed databases (Nolley and Brown, 2015) to demultiplex sequences, cutadapt

209 (Martin, 2011) to remove primers, USEARCH (Edgar, 2013) to filter reads and for OTU

210 clustering (97\% ID), mothur (Schloss et al., 2009) for alignment-based quality control, and

211 QIIME (v1.8) (Caporaso et al., 2010) to assign taxonomy, using the green genes 97\% ID OTU

212 taxonomy database (details in Supplementary Note 2). For the ITS2 data, we processed them as

213 for the 16S data, drawing on methods from (Bálint et al., 2014; Glassman et al., 2015), with the

214 addition of using ITSx (Bengtsson-Palme et al., 2013) to extract only the fungal ITS2 regions of

215 the reads, and using the UNITE reference database (Kõljalg et al., 2013) at 97\% ID to assign

216 taxonomy (details in Supplementary Note 2). We assigned AMF status to any taxa within the

217 Glomeromycota phylum, and EMF status to taxa identified as EMF by Glassman et al. (2015).

218 These assignments were largely consistent with the results from using the FUNGuild database at

219 the "highly probable" or "probable" confidence rankings (Nguyen et al., 2016).

221 Community structuring processes

222 To determine the dominant processes structuring communities in the minerals and rhizosphere

223 soils, we used the approach described by Stegen et al. (2013). In this framework, ecological

224 processes are classified into the following categories: (i) homogeneous selection (abiotic or 
225 biotic pressures select for the same types of characteristics across communities), (ii) variable

226 selection (abiotic or biotic pressures select for different types of characteristics across

227 communities), (iii) homogenizing dispersal (individuals can move between communities easily),

228 (iv) dispersal limitation (individuals can not move between communities easily), and (v)

229 undominated (population fluctuations are essentially due to weak selection, weak dispersal,

230 and/or random chance events) (Stegen et al., 2013; 2015). Briefly, for each pair of communities

231 (samples), variable or homogeneous selection was first inferred in pairings where the

232 phylogenetic dissimilarity ( $\beta$ Mean Nearest Taxon Distance, $\beta$ MNTD) was significantly higher

$233(\beta \mathrm{NTI}>2, \beta$ Nearest Taxon Index $)$ or lower $(\beta \mathrm{NTI}<-2)$ than null expectations, respectively. In the

234 cases where $|\beta \mathrm{NTI}|<2$, “dispersal limitation" or "homogenizing dispersal” was inferred in

235 pairings where taxonomic dissimilarity was significantly higher $\left(\mathrm{RC}_{\mathrm{Bray}}>0.95\right.$, modified $\mathrm{Raup}-$

236 Crick metric based on Bray-Curtis dissimilarity (Chase et al., 2011)) or lower $\left(\mathrm{RC}_{\mathrm{Bray}}<-0.95\right)$

237 than null expectation, respectively. In the remaining cases $\left(|\beta \mathrm{NTI}|<2\right.$ and $\left.\left|\mathrm{RC}_{\mathrm{Bray}}\right|<0.95\right)$, other

238 stochastic processes were considered to be the governing processes ("undominated"). We used

239 the same null model algorithms as Stegen et al. $(2013,2015)$, but improved the estimation of

240 OTU relative abundances in the metacommunity in the null model as follows: the relative

241 abundance of each OTU in each sample was weighted by estimated biomass amount (according

242 to DNA concentrations) in this type of material in the whole microcosm, to calculate relative

243 abundance of each OTU in the metacommunity. The null model analyses were done within each

244 sampling timepoint, separately. The relative importance of a process was measured as the

245 percentage of comparisons dominated by each process, in all comparisons among communities

246 within soil samples or between mineral and soil samples, for each mineral type. We report the

247 comparisons of each mineral type to soil samples, since we are most interested in the processes

248 that determined how minerals and soil communities were interacting.

250 In addition to the $\beta \mathrm{NTI}$ and the $\mathrm{RC}_{\mathrm{Bray}}$, we calculated the nearest taxon index (NTI) and net

251 relatedness index (NRI) individually for each sample (Webb et al., 2002), with 1000

252 randomizations, using the picante package (Kembel et al., 2010) in R (R Core Team). NRI

253 characterizes the mean phylogenetic distance of taxa in a sample from those in all other samples.

254 NTI characterizes the phylogenetic distance from one taxon to the nearest taxon for each taxon in

255 the sample. NRI is a measure of overall clustering, while NTI is more indicative of terminal 
clustering (Webb et al., 2002).

\section{Statistical analyses}

258 To determine significant differences between minerals and soil for DNA extractions and qPCR

259 results, we performed single-factor ANOVAs and Tukey's HSD in R (R Core Team), log-

260 transforming qPCR copy numbers to maintain assumptions of normality. To characterize

261 differences in community composition between samples, we performed a non-metric

262 multidimensional scaling (NMDS) analysis on Bray distances between samples, with OTU

263 counts transformed to relative abundance, using the vegan package in R (Oksanen et al.), with

$264 \mathrm{k}=3$. To determine whether the differences in NMDS plots were significant, we performed a

265 permutational multivariate ANOVA on Bray distances using the vegan package in R (Oksanen et

266 al.) (Supplementary Notes 2 and 3). To determine which taxa significantly increased or

267 decreased in relative abundance in the minerals, compared to in the soil, we used DESeq2 (Love

268 et al., 2014). We calculated differential abundances for all OTUs for each mineral vs. the soil for

269 each timepoint (see Supplementary Notes 4 and 5 for details on outlier OTUs, which DESeq2

270 excludes based on a Cook's distance identification of outliers, and independent filtering).

272 To evaluate possible relationships between differential abundances in the minerals vs. the soils

273 and $16 \mathrm{~S}$ copy number, we predicted $16 \mathrm{~S}$ copy number for each OTU using the ribosomal RNA

274 number database (rrnDB-4.4.3) (Stoddard et al., 2015; Lee et al., 2009). Briefly, we assigned

275 taxonomic names to our OTUs using the Ribosomal Database Project (RDP) database, searched

276 the rrnDB to determine if that genus was included in the database, and if it was, recorded the

277 mean $16 \mathrm{~S}$ copy number known for that genus. We note this is only a rough predictor of copy

278 number, since there is known variation even within a single genus, and we were limited by the

279 taxa included in the database. Thus, results should be interpreted with some caution. To evaluate

280 the relationship between 16 S copy number and differential abundance, we built a linear model,

281 using copy number and mineral type with an interaction with phylum as predictive factors for

282 differential abundance $v s$. soil using the $l m$ function in the R package "vegan" (Oksanen et al.).

284 Because mineral bags were placed in direct contact with growing roots, we expected that the

285 rhizosphere would be a key source of mineral colonizers. To assess whether the bacteria we

286 identified as successful mineral colonizers are generally successful in the rhizosphere, we drew 
on a previous experiment, where Avena fatua (a close relative of Avena barbata) was grown in the same soil as this experiment, and bulk and rhizosphere soils were sampled and analyzed over two growing seasons to determine members of the "dynamic rhizosphere" (Shi et al., 2015).

290 Briefly, we took the sequences from the OTUs that were identified as being enriched in any of

291 the mineral samples, and used USEARCH (Edgar, 2013) to cluster the 16S sequences of the

292 OTUs from the dynamic rhizosphere with these mineral-enriched OTUs, using a 97\% identity 293 cutoff.

\section{Results}

\section{Mineral colonization}

298 We extracted significantly more DNA from whole soil than from all mineral types and the heavy 299 fraction (Figure 2). Of the minerals, we extracted significantly more DNA from ferrihydrite and 300 the heavy fraction, and the least from kaolinite. Any kaolinite samples that had DNA extraction 301 and amplification levels below blank controls were excluded from our analyses. These trends

302 were generally mirrored in $16 \mathrm{~S}$ copies (bacterial and archaeal) (Figure 2) and ITS copies (fungal)

303 (Figure 2), as determined by qPCR. These trends remained similar when considered on a surface 304 area basis (Supplementary Figure 1).

305
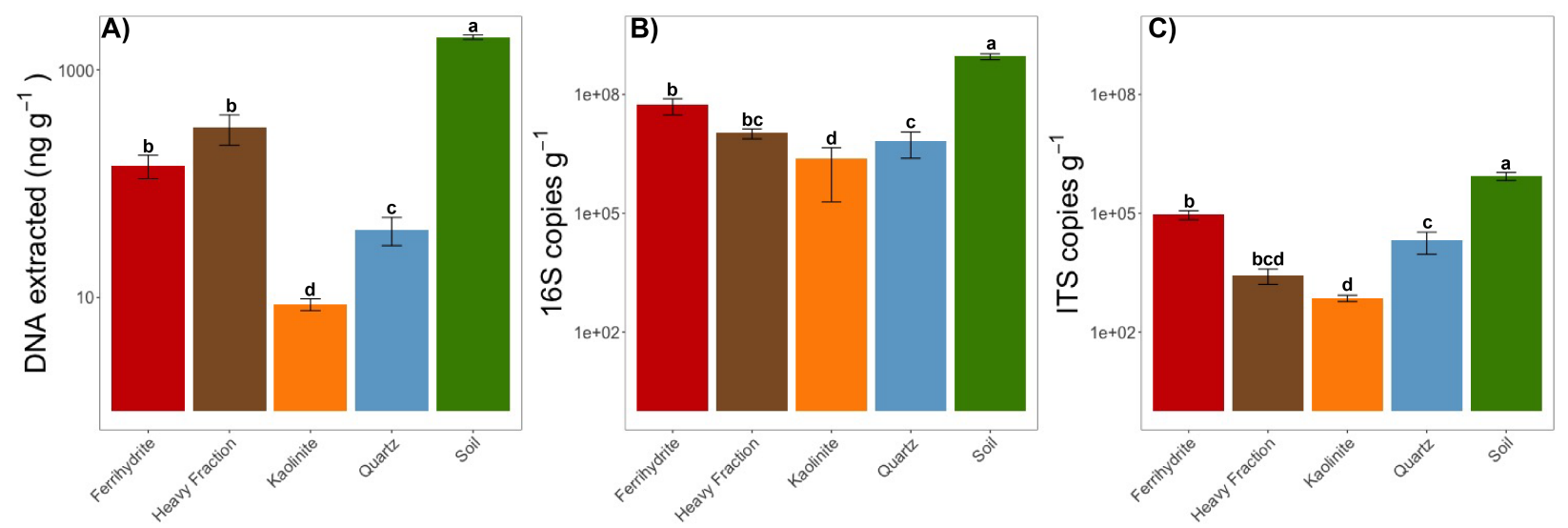

307 Figure 2. (A) DNA extracted from soils and minerals; (B) 16S copies; (C) ITS copies. Mean values after 2-2.5 months after the start of the experiment, with error bars representing $\pm \mathrm{SE}$ ( $\mathrm{n}=3$

309 for heavy fraction, $\mathrm{n}=8-23$ for all other minerals). Note $\log$ scales. Lowercase letters indicate 310 significant differences ( $<<0.05$, ANOVA, Tukey's HSD). 


\section{Community comparisons}

312 Community composition differed significantly by mineral type (Figure 3 ) for both fungi and

313 bacteria/archaea. There was significant effect of mineral type on Bray-Curtis distances between

314 samples for both fungi and bacteria/archaea (Supplementary Figures 2 and 3; permutational

315 multivariate ANOVA, $\mathrm{p}<0.001$ ). While there were significant changes in community

316 composition over time $(\mathrm{p}<0.08$ for bacteria/archaea and $\mathrm{p}<0.004$ for fungi), these were not

317 dramatic. For the remaining analyses, we present results from the 2 and 2.5 month time-points

318 combined, as they were not significantly different in community composition $(\mathrm{p}<0.12$ for both

319 fungi and bacteria/archaea), had similar levels of diversity (Supplementary Figure 4), and had

320 more DNA extracted than the 1 month time-point (Supplementary Figures 5 and 6).
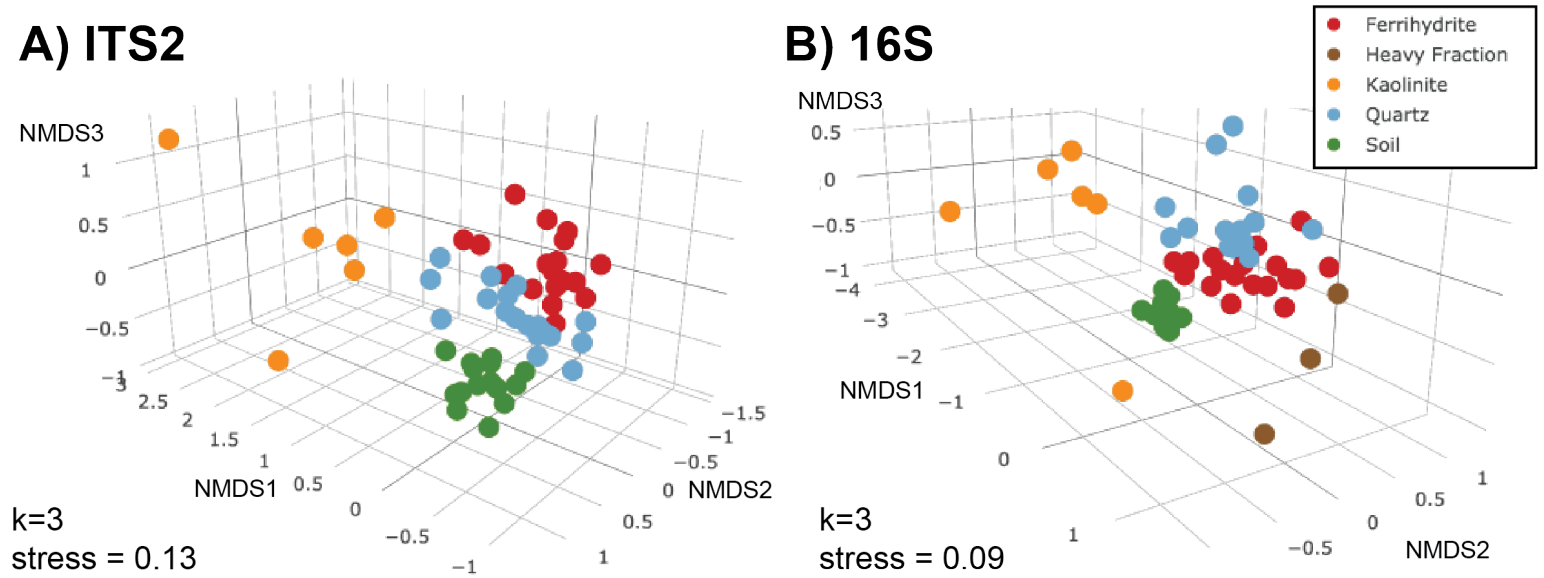

323 Figure 3. Three-dimensional NMDS plots of Bray distances for A) fungal ITS2 ( $k=3$,

324 stress $=0.13)$ and $\mathrm{B})$ bacterial/archaeal $16 \mathrm{~S}(\mathrm{k}=3$, stress=0.09) communities, along with bulk soil

325 samples.

327 Community composition

328 At the bacterial phylum level, all samples were dominated by Proteobacteria, Actinobacteria,

329 Bacteroidetes, Firmicutes, and Acidobacteria (Figure 4). The mineral microbial communities

330 were significantly lower in relative abundance of Acidobacteria, Planctomycetes, and

331 Gemmatimonadetes than was the soil community. 

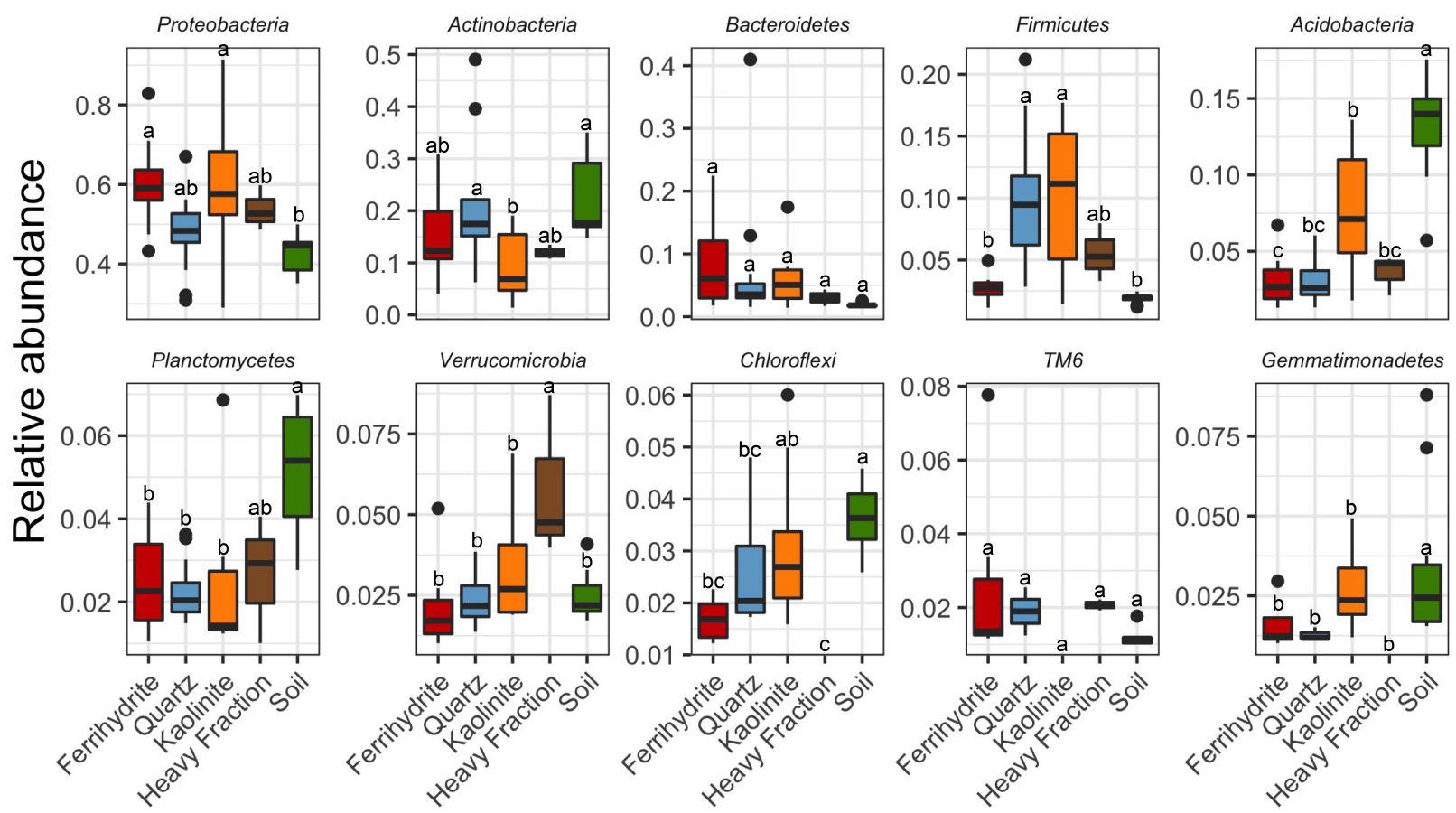

335 fraction, $\mathrm{n}=3$; for all others $\mathrm{n}=11-14$. Letters indicate significant differences within a phylum

$336(\mathrm{p}<0.05$, ANOVA, Tukey’s HSD).

338 Fungal communities were dominated by Ascomycetes and Basidiomycetes, although large

339 fractions (up to $40 \%$ in kaolinite minerals) were not identifiable using the UNITE database even

340 at the phylum level. At a finer taxonomic level, the most abundant orders (for those taxa

341 identifiable to order) were Sordariales, Eurotiales, and Hypocreales. The orders Sordariales and

342 Eurotiales had significantly lower relative abundances in the minerals as compared to the soils,

343 and orders Sebacinales and Glomerales had significantly higher relative abundances in the

344 ferrihydrite minerals than the soils (Figure 5 and Supplementary Figure 7). 

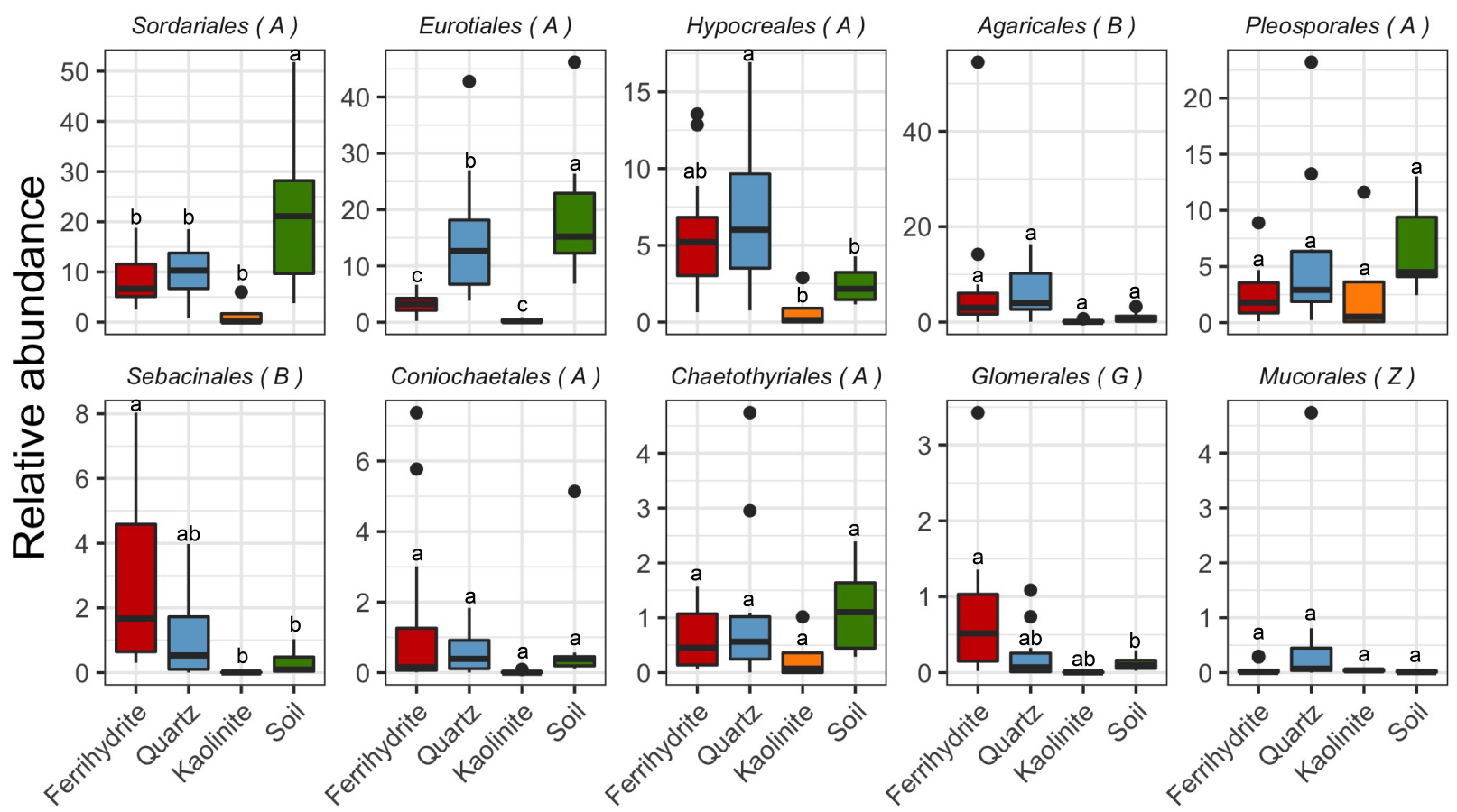

Figure 5. Relative abundance of top 10 fungal orders in different mineral types. Phylum is indicated in brackets: "A" = Ascomycota, "B" = Basidiomycota, "G" = Glomeromycota, "Z" = Zygomycota. For kaolinite, $n=4$; for all others $n=10-14$. Letters indicate significant differences within an order ( $\mathrm{p}<0.05$, ANOVA, Tukey's HSD).

\section{Differential abundance}

353 The relative abundance of mineral-associated microbial communities differed from that of the

354 soil community. In the bacteria/archaea, 39\% of all OTUs were significantly enriched in at least one mineral as compared to the soil, while $27 \%$ were significantly depleted. $75 \%$ of all OTUs were neither significantly enriched, nor significantly depleted in any mineral as compared to the soil. Acidobacteria tended to be depleted in the ferrihydrite and the quartz minerals, while Firmicutes and Bacteroidetes tended to be enriched (Supplementary Figures 8 and 9). Actinobacteria, Proteobacteria, and Verrucomicrobia all showed both positive and negative responses. In the fungi, $9 \%$ of all OTUs were significantly enriched in at least one mineral as compared to the soil, while $14 \%$ were significantly depleted in at least one mineral. $92 \%$ of all

362 OTUs were neither significantly enriched, nor significantly depleted in any mineral as compared

363 to the soil. Glomeromycota, the arbuscular mycorrhizal fungi, were consistently enriched in

364 relative abundance in the ferrihydrite minerals, but not the quartz or kaolinite (Supplementary 
365 Figures 10 and 11), while there was a broader range of responses for the Ascomycota and

366 Basidiomycota.

368 In order to examine these responses at a finer phylogenetic resolution, we plotted the OTUs for

369 which there was a significant $(\mathrm{FDR}<0.1)$ response of $4 \mathrm{x}$ or greater $\left(\log _{2}\right.$-fold change $\left.=2\right)$,

370 grouped by family (Supplementary Figure 12). Of these taxa, Burkholderiaceae,

371 Chitinophagaceae, Comamonadaceae, Phyllobacteriaceae, Rhizobiaceae, Rhodospirillaceae,

372 and Streptomycetaceae were enriched in both the ferrihydrite and quartz minerals, while and

373 Bacillaceae were only enriched in the quartz minerals. In the heavy fraction, we also noted the

374 enrichment of candidate family Chthoniobacteraceae, which was dominated by the putative

375 bacterial nematode symbiont Candidatus Xiphinematobacter sp (Vanderkerckhove et al., 2015).

376

377 We were not able to taxonomically resolve the fungi as well as the bacteria and archaea. The

378 ITS2 region diverges at too fine of a genetic scale to match ITS2 sequences to phylogenetic

379 levels coarser than species- or genus-level. Thus, a large fraction ( $>50 \%$ in some samples) of

380 responding taxa were not identifiable taxonomically. Of the identified taxa, OTUs that matched

381 Serendipita and Pochonia both stood out as strong responders in both ferrihydrite and quartz

382 minerals (Supplementary Figure 13). OTUs that best matched Agaricales were also enriched in

383 quartz, while OTUs that best matched Sebacinales were also enriched in ferrihydrite.

384 Trichosporon was identified as being enriched in the kaolinite minerals.

385

386 Prior work suggests the potential for a bacterial taxon to grow quickly or be a strong early

387 colonizer correlates with 16S copy number (Goldfarb et al., 2011Nemergut et al., 2016). 16S

388 copy number was significantly correlated with $\log _{2}$-fold change in relative abundance in minerals

$389 v s$. soil, controlling for phylum and mineral type (Supplementary Figure 14) (ANOVA,

$390 \mathrm{p}<0.0001, \mathrm{R}_{\text {adj }}^{2}=0.28$ ). There were not significant interactions between mineral type and $16 \mathrm{~S}$

391 copy number.

392

393 In order to determine whether the bacteria that we identified as successful mineral colonizers

394 were simply the same subset of soil bacteria that were successful in the Avena sp. rhizosphere,

395 we compared our results to those of (Shi et al., 2015), which studied the same soil and Avena 
396 fatua (a close relative of Avena barbata). Of the OTUs that were significantly enriched in the

397 mineral samples, only $8 \%$ (kaolinite) to $18 \%$ (heavy fraction) were also identified as members of

398 the dynamic rhizosphere (Shi et al., 2015) (Supplementary Figures 15 and 16). One notable

399 difference is the Firmicutes phylum, which contains important mineral colonizers, but not

400 notable rhizosphere responders. Of the OTUs common to both the minerals and the rhizosphere,

401 most were from the phyla Proteobacteria (50\%), Actinobacteria (16\%), or Bacteroidetes (13\%)

402 (Supplementary Figure 17).

403

404 Community assembly

405 The dominant process governing community assembly across the soil $16 \mathrm{~S}$ communities within a

406 given time-point was homogenizing selection (abiotic or biotic pressures select for the same

407 types of characteristics across communities; Figure 6). Homogenizing selection also played a

408 role in the assembly of quartz and ferrihydrite communities as compared to soil communities.

409 Interestingly, dispersal limitation played dominant roles in controlling community assembly on

410 all mineral surfaces (Fig. 6). However, in contrast to other mineral surfaces, variable selection

411 played a role in governing microbial community structure on kaolinite minerals (Fig. 6).

412 Incorporating OTU relative abundance in the metacommunity null model analyses with Bray-

413 Curtis dissimilarity did not substantially change the trends (Supplementary Figure 18). Mean

414 NTI and NRI both indicated significant phylogenetic clustering for all mineral types

415 (Supplementary Figures 19 and 20). 


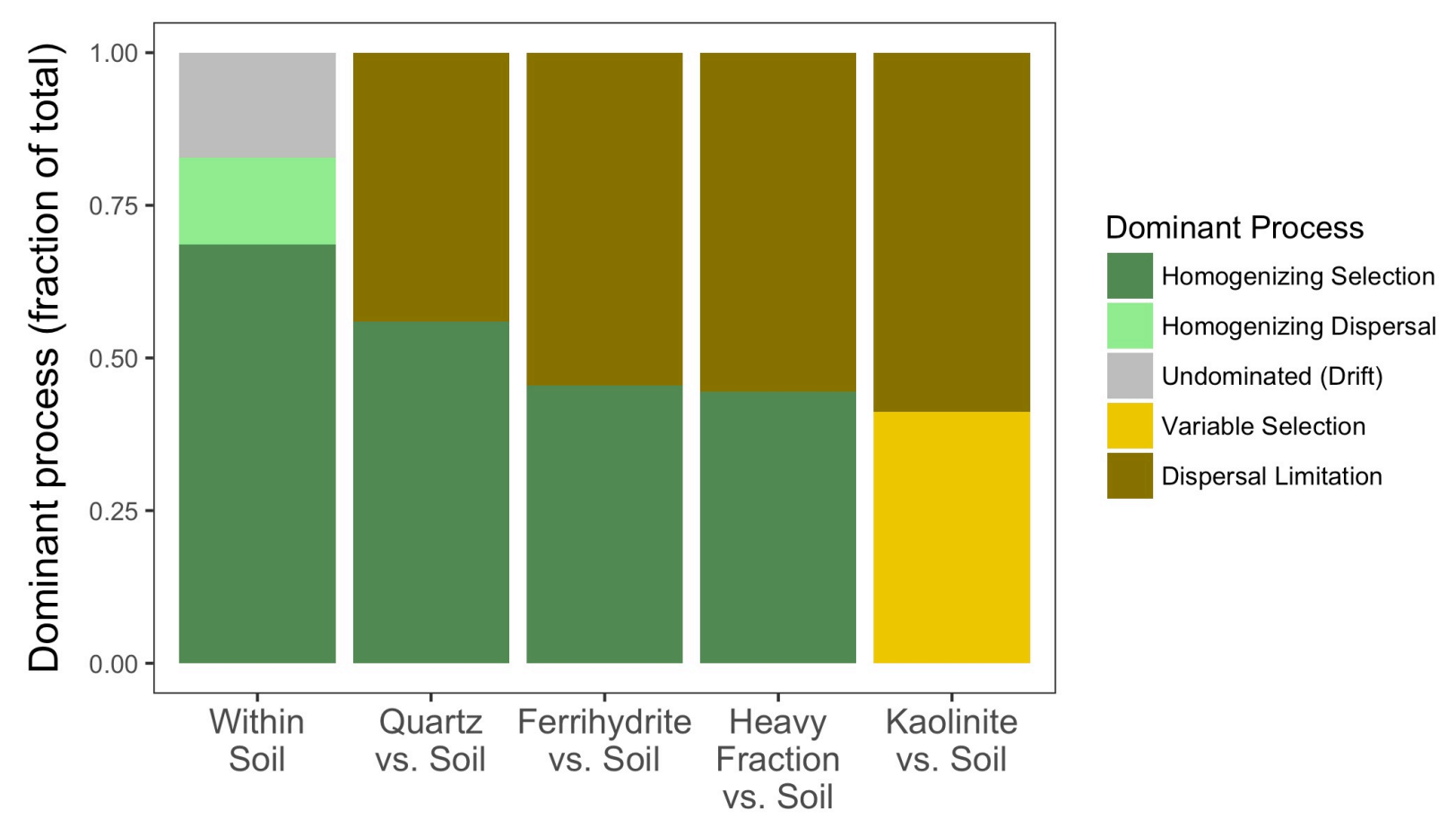

418 Figure 6. Relative influence of different community assembly processes on spatial turnovers

419 among soil communities and between soil communities and those on different mineral surfaces.

420 The governing processes were determined using $\mathrm{RC}_{\mathrm{Bray}}$ and $\beta \mathrm{NTI}$ (Stegen et al., 2013). Different

421 colors represent different the fraction of community turnovers governed by each process.

\section{Discussion}

425 Mineral specificity in microbial community assembly

426 The mechanisms enabling colonization of soil minerals are likely foundational to the overall soil

427 microbiome composition and partially responsible for the persistence of $\mathrm{C}$ entering soil via plant

428 roots. Our results were consistent with previous studies (Wilson et al., 2008; Hutchens et al.,

429 2010; Gleeson et al., 2006; 2005), in that different minerals harbored significantly different

430 bacterial/archaeal and fungal communities (Figure 3), with evidence for selection based on

431 phylogenetic lineage (Supplementary Figures 18 and 19) - i.e., communities have a stronger

432 phylogenetic signal than would be expected by chance. Microbial colonization was likely highest

433 in the ferrihydrite minerals, as we were able to extract significantly more DNA from ferrihydrite

434 than the quartz or kaolinite (Figure 2 and Supplementary Figures 5 and 6). This is also consistent

435 both with other studies, which showed increased microbial biomass on Fe-containing minerals 
436 (Wilson et al., 2008), and with our own findings (Neurath et al., in prep), which showed that

437 ferrihydrite accumulated the most total C. While kaolinite accumulated a comparably high mass

438 of $\mathrm{C}$ on a mineral mass basis, when normalized by surface area, it was dramatically lower than

439 that of ferrihydrite (Neurath et al., in prep). In addition, the mineral morphology could

440 potentially accentuate the differences in surface accessibility - the platy structure of clay stacks

441 very differently than the granular ferrihydrite or quartz (Neurath et al., in prep). The significant

442 differences in the microbial communities that colonize different minerals suggest that

443 mineralogy in natural soils may also be important in determining microbial community structure,

444 with potential implications for biogeochemical cycling and persistence of soil organic matter.

446 Possible mechanisms of microbial colonization of fresh minerals

447 Our null hypothesis was that there would be no meaningful dispersal limitations or selective

448 pressures associated with mineral colonization. The null hypothesis would be consistent with

449 microbes being swept passively onto the minerals with the movements of soil water, and we

450 would have expected that the resulting communities should largely resemble those of the source

451 soil. However, we found that dispersal limitation was an important factor shaping the differences

452 of mineral communities from soil communities, for all mineral types (Figure 6) - that is, in one

453 growing season of an annual grass (2.5 months), a large portion of soil microbes will not be

454 expected reach the minerals by neutral dispersal. Thus, we hypothesize that while this may

455 simply indicate that spatial proximity to minerals may be a key factor in successful colonization,

456 some of the first successful colonizers might be capable of active movement to the minerals. This

457 would require the expression of flagella or other motility factors, such as swarming (Dechesne et

458 al., 2010) and sufficient soil water to support bacterial movement. In addition, water movement

459 by diffusion or advection into and out of the mineral bags could have differed between bags and

460 between bags and the soil. Thus, differences in patterns and processes of water movement may

461 also be responsible for some of the observed differences. Microbes could also be transported to

462 new mineral surfaces by other organisms. For example, we found enrichment of the putative

463 fungal parasite of nematode eggs, Pochonia (Supplementary Figure 13) (Kerry and Hirsch,

464 2011), and the bacterial nematode symbiont Candidatus Xiphinematobacter sp. in minerals.

465 While Candidatus Xiphinematobacter sp. is thought to be a maternally-transferred obligate

466 symbiont (Lazarova et al., 2016), and so is not likely directly colonizing the minerals, it 
467 highlights the potential for movement of soil fauna enabling rapid dispersal of their associated 468 fungi and bacteria.

470 Once microbes have arrived at fresh mineral surfaces, fast-growing microbes may predominate,

471 by winning the competition for new surface area (Converse et al., 2015). There was a significant

472 positive correlation between enrichment on minerals and predicted 16S copy number

473 (Supplementary Figure 14). 16S copy number has been linked to fast-growth strategies (Goldfarb 474 et al., 2011) and early succession (Nemergut et al., 2016). In addition to fast-growers, organisms 475 that can thrive in environments with low OM may have a colonization advantage, since the 476 minerals are initially low-nutrient environments and high OM may actually inhibit bacterial 477 adhesion to soil particles (Zhao et al., 2014). This low-nutrient, low-OM environment in the 478 mineralosphere could partly explain why there was $<20 \%$ overlap in mineral-enriched OTUs 479 with those identified as part of the "dynamic rhizosphere" in a very similar system (Shi et al., 480 2015) (Supplementary Figures 15-17). While high 16S copy number Firmicutes were 481 consistently enriched in the minerals (Supplementary Figures 8 and 9), they were rarely found 482 among the dynamic rhizosphere taxa (Supplementary Figure 17). Thus, some of the 483 characteristics that make a microbe a strong colonizer of new microhabitats in the soil may be 484 different from those that make it a strong responder to roots. For example, while the nutrient 485 environment in the minerals might be expected to reflect that of the rhizosphere in its 486 composition, the total amount of $\mathrm{C}$ and other nutrients available were likely dramatically lower 487 in the minerals. One source of nutrients and energy could be the first colonizers of the minerals 488 themselves; possible predatory bacteria such as Cytophaga and Bdellovibrio, or the possible 489 fungal predator/endosymbiont Chitinophaga (Shaffer et al., 2017) were consistently and 490 sometimes dramatically increased in relative abundance in minerals (Supplementary Note 6 and 491 Supplementary Figure 21). Another way to survive in sparse environments could be to access 492 resources from elsewhere via filamentous growth. Significant fungal colonizers of minerals 493 include mycorrhizal symbionts. Unlike saprotrophic fungi, they have a direct plant-derived C 494 source, and so can possibly better "afford" to explore the low-C mineral environments.

495 Supporting this idea, we found that AMF were enriched in ferrihydrite minerals (Supplementary

496 Figures 11 and 22), and Sebacinales and Serendipita vermifera (possible mycorrhizal fungi) 497 were significantly enriched in ferrihydrite and quartz (Supplementary Figure 12). AMF could 
498 potentially act as a sort of shunt of $\mathrm{C}$ from the plants to the fresh minerals, paving the way for

499 future mineral colonizers. Mineral-colonizing fungi may directly provide a source of $\mathrm{C}$ for

500 bacteria - one of the most mineral-enriched OTUs ( $\log _{2}$-fold changes of 7.3 and 4.0 in

501 ferrihydrite and quartz, respectively, and representing $>1 \%$ of the total community in

502 ferrihydrite) was identified as Chitinophaga sp. (a possible consumer or endosymbiont of fungi

503 (Shaffer et al., 2017)) and was also part of the dynamic rhizosphere (Supplementary Figure 21).

504 Unlike AMF, we found that predicted saprotrophic fungi (Nguyen et al., 2016) tended to be

505 depleted in ferrihydrite (Supplementary Figure 22), likely because there was little C there on

506 which they could subsist. However, while we might have predicted that fungi would generally be

507 better colonizers of the sparse mineral environments than bacteria/archaea, due to their ability to

508 draw on resources elsewhere through their hyphae, this was not supported by the qPCR data.

509 There were not significant differences in the 16S vs. ITS copy number ratios between quartz or

510 ferrihydrite and soils, and the heavy fraction and kaolinite minerals actually had significantly

511 higher 16S vs. ITS copy number ratios than were found in soils (Supplementary Figure 23).

512 Furthermore, Actinobacteria were not consistently enriched in minerals, although they can often

513 exhibit filamentous growth similar to that of fungi. Thus, filamentous growth alone may not be a

514 reliable predictor of greater colonization success - a robust $\mathrm{C}$ source (such as that secured

515 through symbiosis) may also be required.

517 In addition to dispersal limitation, homogeneous selection was an important factor for all

518 minerals except for kaolinite, which was influenced by variable selection, as compared to the soil

519 communities. While the explanation for homogeneous selection is likely relatively

520 straightforward - certain features of quartz and ferrihydrite resemble those of the soil, and result

521 in similar environments with similar selective pressures - there may be a few possible

522 explanations for the variable selection in kaolinite. These explanations could include various

523 ways in which the kaolinite environment was more different from that of the background soil

524 than were the quartz and ferrihydrite environments, as discussed in the previous section. For

525 example, dramatically higher surface area and smaller particle size (Table 1), may have created

526 an environment substantially different from that of the background soil. A comparatively sparse

527 distribution of resources on kaolinite minerals, given their high surface are, could have resulted

528 in stronger selective pressure for arriving microbes, also contributing to the greater importance of 
529 variable selection and competition in these communities (Figure 6). Additionally, the difference

530 in the environments inside vs. the outside of the mineral bags may have been greater for kaolinite

531 than for the other minerals, due to its very small particle size, further differentiating the kaolinite

532 environment.

533

534 Our study examines the initial stages of microbial colonization on minerals over a single growing

535 season. Future work following these trends over a longer period of time could address whether

536 dispersal limitation plays a meaningful long-term role in structuring soil mineral communities -

537 do the bacteria that arrive first continue to prevail in the community? This hypothesis may be

538 supported by the observation that the bacterial communities in minerals were more variable than

539 those in the bulk soil (Figure 3 and Supplementary Figures 24 and 25) - suggesting that there is

540 variability in which specific microbes happen to first colonize the fresh minerals. However, only

541 future studies spanning multiple plant growing seasons could determine how long these

542 assemblages might persist, and whether the arrival and establishment of the first sets of microbes

543 could result in exclusion of future potential colonists, or whether the minerals would quickly

544 come to resemble the bulk soil community.

545

546 An additional confounding factor is that the soil community represented by ribosomal DNA is an

547 integrated profile of the historical soil microbial community, not just active, or even living,

548 microbes (Blazewicz et al., 2013; Carini et al., 2016). After years in the soil, cycling through

549 disturbances and environmental changes, the apparent (historical) diversity of microbes on the

550 minerals would also be expected to increase, simply as the microbial record of environmental

551 change accumulates. However, bulk soil has more diverse mineralogy than the homogeneous

552 minerals, and, thus, more diverse microenvironments, so some of these differences may persist.

553 For example, we did not seem to see convergence of mineral and soil communities over the 2.5-

554 months of this experiment (Figure 3).

555

556 Conceptual model

557 While microbial communities associated with the fresh minerals broadly resembled the source

558 soil communities (Figures 2-5), significant phylogenetic differences between mineral and soil

559 communities reveal that community assembly on fresh soil minerals is governed by multiple 
560 processes. While we expect passive transport of microbes to fresh mineral surfaces by soil water

561 movements occurs, some microbes are likely actively moving or transported to minerals (Figure

562 6). Once they encounter the minerals, certain microbes become significantly enriched on the new

563 mineral surfaces (Supplementary Figures 8-11), due to a wide variety of possible biological,

564 geochemical, and physical drivers (Figure 7).

566 Mechanisms controlling the colonization of mineral surfaces may be factors in determining the

567 overall composition of the soil microbial community as well as the amounts and composition of

568 biomass and SOC associated with mineral surfaces. To the degree that microbial biomass (and

569 necromass) is an origin of persistent soil organic matter, the dynamics of microbial colonization

570 of soil mineral surfaces are foundational to the stabilization of soil organic matter.

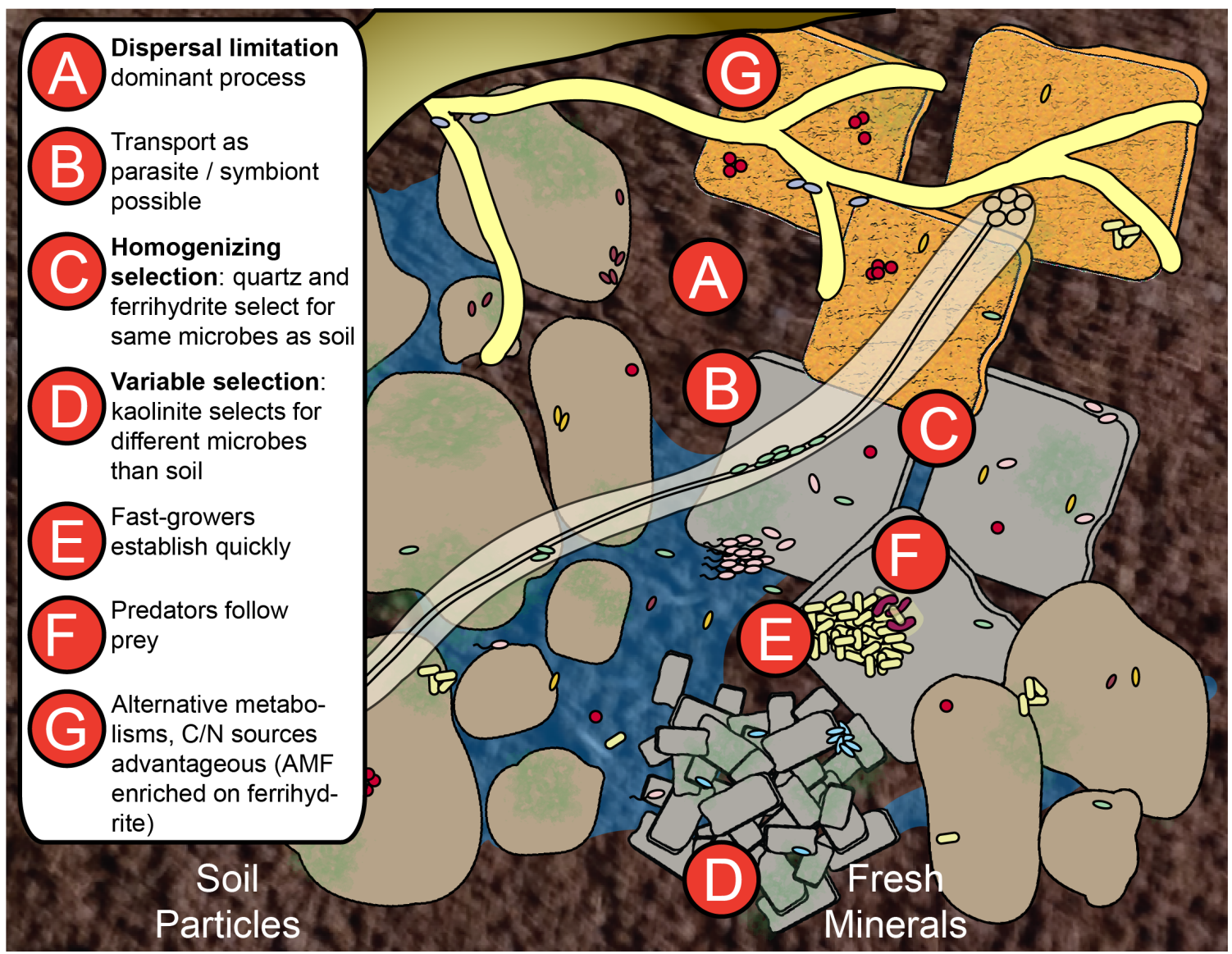

573 Figure 7. Conceptual diagram of mechanisms by which microbes may colonize fresh soil

574 mineral surfaces. Dispersal limitation (A) was the dominant process over the timescale of this

575 experiment, while some microbes are likely actively moving or being transported to minerals 
576 (B). Once microbes encounter the minerals, homogenizing selection structures quartz and

577 ferrihydrite communities (C), while variable selection structures kaolinite communities (D). Fast

578 growth (E), as predicted by predicted $16 \mathrm{~S}$ copy number, predation $(\mathrm{F})$, and other advantageous

579 factors $(\mathrm{G})$ may result in specific microbes becoming significantly enriched on the new mineral

580 surfaces, due to a wide variety of possible biological, geochemical, and physical drivers. 


\section{Acknowledgements}

582 This research is based upon work supported by the U.S. Department of Energy Office of Science,

583 Office of Biological and Environmental Research Genomic Science program under Award

584 Number DE-SC0010570 to UC Berkeley and the University of Oklahoma. Part of this work was

585 performed under the auspices of the U.S. Department of Energy by Lawrence Livermore

586 National Laboratory under contract DE-AC52-07NA27344. The University of California

587 Hopland Research and Extension Center was the source for the soil used here and provided a

588 variety of support services. We thank Katerina Estera, Don Herman, Evan Starr, Shengjing Shi,

589 Erin Nuccio, Anne Kakouridis, and Yonatan Sher for field and lab assistance.

\section{Supplementary information}

592 Supplementary information is available at XXX. Sequences are deposited in the NCBI short read 593 archive (SRA); the accession number is XXX. 


\section{References}

595

596

Banfield JF, Barker WW, Welch SA, Taunton A. (1999). Biological impact on mineral

597 dissolution: application of the lichen model to understanding mineral weathering in the rhizosphere. Proceedings of the National Academy of Sciences 96: 3404-3411.

599 Banfield JF, Hamers RJ. (1997). Processes at minerals and surfaces with relevance to 600 microorganisms and prebiotic synthesis. Geomicrobiology: Interactions Between Microbes and 601 Minerals 35: 81-122.

602 Bálint M, Schmidt P-A, Sharma R, Thines M, Schmitt I. (2014). An Illumina metabarcoding 603 pipeline for fungi. Ecology and Evolution 4: 2642-2653.

604 Belnap J, Hawkes CV, Firestone MK. (2003). Boundaries in Miniature: Two Examples from 605 Soil. BioScience 53: 739.

606 Bengtsson-Palme J, Ryberg M, Hartmann M, Branco S, Wang Z, Godhe A, et al. (2013). Improved software detection and extraction of ITS1 and ITS2 from ribosomal ITS sequences of

608 fungi and other eukaryotes for analysis of environmental sequencing data. Methods Ecol Evol 4: 609 914-919.

610 Blazewicz SJ, Barnard RL, Daly RA, Firestone MK. (2013). Evaluating rRNA as an indicator of 611 microbial activity in environmental communities: limitations and uses. The ISME Journal 7:

612 2061-2068.

613 Caporaso JG, Kuczynski J, Stombaugh J, Bittinger K, Bushman FD, Costello EK, et al. (2010). 614 QIIME allows analysis of high-throughput community sequencing data. Nature Methods 7: 335615336.

616 Carini P, Marsden PJ, Leff JW, Morgan EE, Strickland MS, Fierer N. (2016). Relic DNA is 617 abundant in soil and obscures estimates of soil microbial diversity. e-pub ahead of print, doi: $618 \quad 10.1101 / 043372$.

619 Chase JM, Kraft N, Smith KG, Vellend M. (2011). Using null models to disentangle variation in 620 community dissimilarity from variation in $\alpha$-diversity. Ecosphere.

621 Chen J, Blume HP, Beyer L. (2000). Weathering of rocks induced by lichen colonization-a 622 review. CATENA 39: 121-146.

623 Clemmensen KE, Bahr A, Ovaskainen O, Dahlberg A, Ekblad A, Wallander H, et al. (2013). 624 Roots and Associated Fungi Drive Long-Term Carbon Sequestration in Boreal Forest. Science 625 339: 1615-1618.

626 Converse BJ, McKinley JP, Resch CT, Roden EE. (2015). Microbial mineral colonization across 627 a subsurface redox transition zone. Frontiers in Microbiology 6: 858.

628 Cooper R, Rudolph ED. (1953). The Role of Lichens in Soil Formation and Plant Succession. 
630 DeAngelis KM, Brodie EL, DeSantis TZ, Andersen GL, Lindow SE, Firestone MK. (2008).

631 Selective progressive response of soil microbial community to wild oat roots. The ISME Journal

632 3: 168-178.

633 Dechesne A, Wang G, Gulez G, Or D, Smets BF. (2010). Hydration-controlled bacterial motility 634 and dispersal on surfaces. Proc Natl Acad Sci USA 107: 14369-14372.

635 Dijkstra FA, Cheng W. (2007). Interactions between soil and tree roots accelerate long-term soil 636 carbon decomposition. Ecology Letters 10: 1046-1053.

637 Drake JA. (1990). The Mechanics of Community Assembly and Succession. Journal of 638 Theoretical Biology 147: 213-233.

639 Drake JE, Gallet Budynek A, Hofmockel KS, Bernhardt ES, Billings SA, Jackson RB, et al. 640 (2011). Increases in the flux of carbon belowground stimulate nitrogen uptake and sustain the 641 long-term enhancement of forest productivity under elevated CO2. Ecology Letters 14: 349-357.

642 Edgar RC. (2013). UPARSE: highly accurate OTU sequences from microbial amplicon reads. 643 Nature Methods 10: 996-998.

644 Fierer N, Jackson JA, Vilgalys R, Jackson RB. (2005). Assessment of Soil Microbial Community 645 Structure by Use of Taxon-Specific Quantitative PCR Assays. Applied and Environmental 646 Microbiology 71: 4117-4120.

647 Gadd GM. (2010). Metals, minerals and microbes: geomicrobiology and bioremediation.

648 Microbiology 156: 609-643.

649 Glassman SI, Peay KG, Talbot JM, Smith DP, Chung JA, Taylor JW, et al. (2015). A continental 650 view of pine-associated ectomycorrhizal fungal spore banks: a quiescent functional guild with a 651 strong biogeographic pattern. New Phytologist 205: 1619-1631.

652 Gleason HA. (1939). The Individualistic Concept of the Plant Association. American Midland 653 Naturalist 21: 92.

654 Gleeson DB, Clipson N, Melville K, Gadd GM, McDermott FP. (2005). Characterization of 655 fungal community structure on a weathered pegmatitic granite. Microbial Ecology 50: 360-368.

656 Gleeson DB, Kennedy NM, Clipson N, Melville K, Gadd GM, McDermott FP. (2006).

657 Characterization of Bacterial Community Structure on a Weathered Pegmatitic Granite.

658 Microbial Ecology 51: 526-534.

659 Griffiths RI, Whiteley AS, O'Donnell AG, Bailey MJ. (2000). Rapid method for coextraction of 660 DNA and RNA from natural environments for analysis of ribosomal DNA- and rRNA-based 661 microbial community composition. Applied and Environmental Microbiology 66: 5488-5491.

662 Hansel CM, Benner SG, Neiss J, Dohnalkova A, Kukkadapu RK, Fendorf S. (2003). Secondary 
663 mineralization pathways induced by dissimilatory iron reduction of ferrihydrite under advective 664 flow. Geochimica et Cosmochimica Acta 67: 2977-2992.

665 Hodkinson ID, Webb NR, Coulson SJ. (2002). Primary community assembly on land - the 666 missing stages: why are the heterotrophic organisms always there first? J Ecol 90: 569-577.

667 Hutchens E. (2009). Microbial selectivity on mineral surfaces: possible implications for 668 weathering processes. Fungal Biology Reviews 23: 115-121.

669 Hutchens E, Gleeson D, McDermott F, Miranda-CasoLuengo R, Clipson N. (2010). Meter-Scale 670 Diversity of Microbial Communities on a Weathered Pegmatite Granite Outcrop in the Wicklow 671 Mountains, Ireland; Evidence for Mineral Induced Selection? Geomicrobiology Journal 27: 167214.

673 Jaeger C, Lindow S, Miller W, Clark E, Firestone M. (1999). Mapping of sugar and amino acid 674 availability in soil around roots with bacterial sensors of sucrose and tryptophan. Applied and 675 Environmental Microbiology 65: 2685-2690.

676 Oksanen J, Blanchet FG, Kindt R, Legendre P, Minchin PR, O'Hara RB, et al. (2015). vegan:

677 Community Ecology Package. R package version 2.3-0. http://CRAN.R-

678 project.org/package=vegan

679 Kallenbach CM, Frey SD, Grandy AS. (2016). Direct evidence for microbial-derived soil organic 680

681 Keddy PA. (1992). Assembly and Response Rules: Two Goals for Predictive Community 682 Ecology. Journal of Vegetation Science 3: 157-164.

683 Keiluweit M, Bougoure JJ, Nico PS, Pett-Ridge J, Weber PK, Kleber M. (2015). Mineral

684 protection of soil carbon counteracted by root exudates. Nature Climate Change 5: 588-595.

685 Kõljalg U, Nilsson RH, Abarenkov K, Tedersoo L, Taylor AFS, Bahram M, et al. (2013).

686 Towards a unified paradigm for sequence-based identification of fungi. Mol Ecol 22: 5271-5277.

687 Kögel-Knabner I, Guggenberger G, Kleber M, Kandeler E, Kalbitz K, Scheu S, et al. (2008).

688 Organo-mineral associations in temperate soils: Integrating biology, mineralogy, and organic 689 matter chemistry. Journal of Plant Nutrition and Soil Science 171: 61-82.

690 Kuzyakov Y, Blagodatskaya E. (2015). Microbial hotspots and hot moments in soil: Concept \& 691 review. Soil Biology and Biochemistry 83: 184-199.

692 Lee ZMP, Bussema C, Schmidt TM. (2009). rrnDB: documenting the number of rRNA and 693 tRNA genes in bacteria and archaea. Nucleic Acids Reseearch 37: D489-D493.

694 Lehmann J, Kinyangi J, Solomon D. (2007). Organic matter stabilization in soil 695 microaggregates: implications from spatial heterogeneity of organic carbon contents and carbon 696 forms. Biogeochemistry 85: 45-57. 
697 Love MI, Huber W, Anders S. (2014). Moderated estimation of fold change and dispersion for 698 RNA-seq data with DESeq2. Genome Biol 15: 550.

699 Maherali H, Klironomos JN. (2007). Influence of Phylogeny on Fungal Community Assembly 700 and Ecosystem Functioning. Science 316: 1746-1748.

701 Martin M. (2011). Cutadapt removes adapter sequences from high-throughput sequencing reads.

$702 \quad$ EMBnet j 17: 10.

703 McMurdie PJ, Holmes S. (2013). phyloseq: An R Package for Reproducible Interactive Analysis 704 and Graphics of Microbiome Census Data. PLoS ONE 8: e61217.

705 Mekonen A, Sharma P, Fagerlund F. (2013). Transport and mobilization of multiwall carbon

706 nanotubes in quartz sand under varying saturation. Environ Earth Sci 71: 3751-3760.

707 Miltner A, Bombach P, Schmidt-Brücken B, Kästner M. (2011). SOM genesis: microbial

708 biomass as a significant source. Biogeochemistry 111: 41-55.

709 Nguyen NH, Song Z, Bates ST, Branco S, Tedersoo L, Menke J, et al. (2016). FUNGuild: An 710 open annotation tool for parsing fungal community datasets by ecological guild. Fungal Ecology

711 20: 241-248.

712 Nolley A, Brown CT. (2015) screed - short read sequence utils. Michigan State University.

713 Documentation at https://screed.readthedocs.org

714 Nunan N, Wu K, Young IM, Crawford JW, Ritz K. Spatial distribution of bacterial communities 715 and their relationships with the micro-architecture of soil. FEMS Microbiology Ecology 44: 203716215.

717 Oksanen J, Blanchet FG, Kindt R, Legendre P, Minchin PR, OHara RB, et al. vegan:

718 Community Ecology Package.

719 Pepe-Ranney C, Campbell AN, Koechli C, Berthrong ST, Buckley DH. (2015). Unearthing the

721 Pold G, DeAngelis K. (2013). Up Against The Wall: The Effects of Climate Warming on Soil

722 Microbial Diversity and The Potential for Feedbacks to The Carbon Cycle. Diversity 5: 409-425.

723 R Core Team. R: A language and environment for statistical computing.

724 Raab T, Kruemmelbein J, Schneider A, Gerwin W, Maurer T, Naeth MA. (2012). Initial

725 Ecosystem Processes as Key Factors of Landscape Development-a Review. Physical Geography

726 33: 305-343.

727 Ranjard L, Richaume A. (2001). Quantitative and qualitative microscale distribution of bacteria

728 in soil. Res Microbiol 152: 707-716.

729 Raynaud X, Nunan N. (2014). Spatial ecology of bacteria at the microscale in soil. PLoS ONE 9: 
e87217.

731 Saidy AR, Smernik RJ, Baldock JA, Kaiser K, Sanderman J. (2014). Microbial degradation of 732 organic carbon sorbed to phyllosilicate clays with and without hydrous iron oxide coating.

733 European Journal of Soil Science 66: 83-94.

734 Schloss PD, Westcott SL, Ryabin T, Hall JR, Hartmann M, Hollister EB, et al. (2009). Introducing mothur: Open-Source, Platform-Independent, Community-Supported Software for Describing and Comparing Microbial Communities. Applied and Environmental Microbiology

737 75: 7537-7541.

738 Schmidt MWI, Torn MS, Abiven S, Dittmar T, Guggenberger G, Janssens IA, et al. (2011).

739 Persistence of soil organic matter as an ecosystem property. Nature 478: 49-56.

740 Shaffer JP, U'Ren JM, Gallery RE, Baltrus DA, Arnold AE. (2017). An Endohyphal Bacterium 741 (Chitinophaga, Bacteroidetes) Alters Carbon Source Use by Fusarium keratoplasticum (F. solani 742 Species Complex, Nectriaceae). Frontiers in Microbiology 8: 302.

743 Shi S, Nuccio E, Herman DJ, Rijkers R, Estera K, Li J, et al. (2015). Successional Trajectories of

744 Rhizosphere Bacterial Communities over Consecutive Seasons. mBio 6: e00746-15.

745 Six J, Paustian K. (2014). Aggregate-associated soil organic matter as an ecosystem property and 746 a measurement tool. Soil Biology and Biochemistry 68: A4-A9.

747 Sollins P, Swanston C, Kleber M, Filley T, Kramer M, Crow S, et al. (2006). Organic C and N 748 stabilization in a forest soil: Evidence from sequential density fractionation. Soil Biology and 749 Biochemistry 38: 3313-3324.

750 Stegen JC, Lin X, Fredrickson JK, Chen X, Kennedy DW, Murray CJ, et al. (2013). Quantifying 751 community assembly processes and identifying features that impose them. The ISME Journal 7:

752 2069-2079.

753 Stegen JC, Lin X, Fredrickson JK, Konopka AE. (2015). Estimating and mapping ecological 754 processes influencing microbial community assembly. Frontiers in Microbiology 6: 15.

755 Stoddard SF, Smith BJ, Hein R, Roller BRK, Schmidt TM. (2015). rrnDB: improved tools for 756 interpreting rRNA gene abundance in bacteria and archaea and a new foundation for future 757 development. Nucleic Acids Res 43: D593-D598.

758 Tilman D. (2004). Niche tradeoffs, neutrality, and community structure: a stochastic theory of 759 resource competition, invasion, and community assembly. Proceedings of the National Academy 760 of Sciences 101: 10854-10861.

761 Treseder KK, Holden SR. (2013). Fungal Carbon Sequestration. Science 339: 1528-1529.

762 Uroz S, Calvaruso C, Turpault M-P, Frey-Klett P. (2009). Mineral weathering by bacteria:

763 ecology, actors and mechanisms. Trends in Microbiology 17: 378-387. 
764 Uroz S, Kelly LC, Turpault M-P, Lepleux C, Frey-Klett P. (2015). The Mineralosphere Concept:

765 Mineralogical Control of the Distribution and Function of Mineral-associated Bacterial

766 Communities. Trends in Microbiology 23: 751-762.

767 Uroz S, Turpault MP, Delaruelle C, Mareschal L, Pierrat JC, Frey-Klett P. (2012). Minerals

768 Affect the Specific Diversity of Forest Soil Bacterial Communities. Geomicrobiology Journal

769 29: 88-98.

770 Vandekerckhove TTM, Navarro JB, Coomans A, Hedlund BP. (2015). 'Candidatus

771 Xiphinematobacter'. In: Vol. 21. Bergeys Manual of Systematics of Archaea and Bacteria. John

772 Wiley \& Sons, Ltd: Chichester, UK, pp 1-5.

773 Vos M, Wolf AB, Jennings SJ, Kowalchuk GA. (2013). Micro-scale determinants of bacterial

774 diversity in soil. FEMS Microbiol Rev 37: 936-954.

775 White, J T, Bruns TD, Lee SB, Taylor JW. (1990). White, T. J., T. D. Bruns, S. B. Lee, and J. W. 776 Taylor. Amplification and direct sequencing of fungal ribosomal RNA Genes for phylogenetics.

777 In: PCR - Protocols and Applications - A Laboratory Manual. pp 315-322.

778 Wilson MJ, Certini G, Campbell CD, Anderson IC, Hillier S. (2008). Does the preferential microbial colonisation of ferromagnesian minerals affect mineral weathering in soil?

$780 \quad$ Naturwissenschaften 95: 851-858.

781 Wu L, Wen C, Qin Y, Yin H, Tu Q, Van Nostrand JD, et al. (2015). Phasing amplicon 782 sequencing on Illumina Miseq for robust environmental microbial community analysis. $B M C$

783 Microbiology 15: 6578.

784 Xu B, Wingate C, Smith P. (2009). The effect of surface area on the modelling of quartz

785 dissolution under conditions relevant to the Bayer process. Hydrometallurgy 98: 108-115.

786 Young TP, Chase JM, Huddleston RT. (2001). Community Succession and Assembly

787 Comparing, Contrasting and Combining Paradigms in the Context of Ecological Restoration.

788 Ecological Restoration 19: 5-18.

789 Zhang J, Kobert K, Flouri T, Stamatakis A. (2014). PEAR: a fast and accurate Illumina Paired-

790 End reAd mergeR. Bioinformatics 30: 614-620.

791 Zhao W, Walker SL, Huang Q, Cai P. (2014). Adhesion of bacterial pathogens to soil colloidal 792 particles: Influences of cell type, natural organic matter, and solution chemistry. Water Research 793 53: 35-46.

794 Zhou J, Deng Y, Zhang P, Xue K, Liang Y, Van Nostrand JD, et al. (2014). Stochasticity, 795 succession, and environmental perturbations in a fluidic ecosystem. Proc Natl Acad Sci USA 796 111: E836-45. 